OPEN ACCESS

Edited by:

James Lock,

Stanford University, United States

Reviewed by:

Ellen E. Fitzsimmons-Craft, Washington University in St. Louis,

United States

Kathryn Trottier,

University Health Network (UHN),

Canada

*Correspondence:

Melissa Kimber kimberms@mcmaster.ca

Specialty section:

This article was submitted to Psychosomatic Medicine, a section of the journal

Frontiers in Psychiatry

Received: 16 October 2019 Accepted: 29 June 2020

Published: 10 July 2020

Citation:

Kimber M, Gonzalez A and MacMillan HL (2020) Recognizing and Responding to Child

Maltreatment: Strategies to Apply When Delivering Family-Based Treatment for Eating Disorders.

Front. Psychiatry 11:678 doi: 10.3389/fpsyt.2020.00678

\section{Recognizing and Responding to Child Maltreatment: Strategies to Apply When Delivering Family-Based Treatment for Eating Disorders}

\author{
Melissa Kimber $^{1 *}$, Andrea Gonzalez ${ }^{1}$ and Harriet L. MacMillan ${ }^{1,2}$ \\ 1 Offord Centre for Child Studies, Department of Psychiatry and Behavioural Neurosciences, McMaster University, Hamilton, \\ ON, Canada, ${ }^{2}$ Department of Pediatrics, McMaster University, Hamilton, ON, Canada
}

Child maltreatment encompasses a constellation of adverse parental behaviors that include physical, sexual, or emotional abuse, physical or emotional neglect, as well as exposure to violence between parents. A growing body of literature indicates that exposure to child maltreatment is a significant risk factor for the development and maintenance of eating disorders (EDs) and that practitioners experience challenges related to recognizing and responding to various forms of child maltreatment in their practice. Parent-child interactions signifying possible child maltreatment can be subtle; furthermore, the emotional and behavioral symptoms associated with an ED can overlap with those linked with child maltreatment, making it difficult for practitioners to distinguish whether children's symptoms are attributable to underlying psychopathology versus exposure to child maltreatment. This challenge can be further complicated in the context of delivering family-based treatment (FBT); FBT reaffirms that there is no single cause of EDs and asserts the leadership role of parents in their child's recovery process both of which may lead practitioners to inadvertently miss indicators of child maltreatment. In this article, we provide an overview of the evidence linking child maltreatment to EDs among children and adolescents, as well as evidence-informed strategies for practitioners to safely recognize and respond to suspected child maltreatment when delivering FBT to children and adolescents in their practice.

Keywords: child maltreatment, eating disorders, children, adolescents, intervention, mandatory reporting

\section{INTRODUCTION}

Maltreatment in childhood or adolescence is a non-specific risk factor for a substantial proportion of mental disorders detailed in the Diagnostic and Statistical Manual of Mental Disorders (DSM); (1-3) this includes eating disorders (EDs) $(3,4)$. Generally speaking, child maltreatment includes physical, sexual, or emotional abuse, as well as physical and/or emotional neglect by a parent or caregiver (hereafter referred to as "caregiver") toward a child (i.e., under 18 years of age) which results in actual or potential physical or emotional harm to the child. In addition, children's exposure to intimate partner violence (IPV) between adults is increasingly considered a form of 
child maltreatment; (5) its negative impacts are similar to other forms of child abuse and neglect $(3,4,6)$. Table 1 provides a definition for each type of child maltreatment, as well as examples of adverse caregiver behaviors that are characteristic of each child maltreatment type. Importantly, rates of exposure to child maltreatment among individuals with an ED are high relative to population norms, as well as individuals with other types of psychopathology $(8,9)$. In addition, individuals with an ED and a history of maltreatment tend to have earlier ED onset, higher rates of psychiatric comorbidity, a greater frequency of suicidal ideation and attempts, as well as a more severe course of eating-related pathology compared to their non-maltreated peers $(8-10)$. The objectives of this paper are to provide an overview of the evidence linking child maltreatment to EDs among children

TABLE 1 | Types and Examples of Child Maltreatment (7).

\begin{tabular}{lll}
\hline Child Maltreatment & Definition & Example Adverse Parenting Behaviors \\
Sub-type &
\end{tabular}

Physical abuse

Sexual abuse

Emotional abuse

Emotional neglect

Child exposure to intimate partne violence
Includes the use of physical force, a tool or apparatus to physically harm or control a child or adolescent. Physical abuse has also occurred when a parent or caregiver commits an act that can or does result in physical injury to the child or adolescent, including red marks, cuts, welts, bruises, muscle sprains, head injury, and/or broken bones.
- Hitting

- Kicking

- $\quad$ Shaking

- Throwing

- Poisoning

- Burning or scalding

- Drowning

- Suffocating

- Deliberately inducing illness via intentional exposure to known communicable diseases or viruses.

- Inappropriate fondling of the child or touching of any kind.

- Vaginal, anal, or oral rape, or attempted rape.

- Making the child read, watch, hear or participate in sexual acts or pornography.

- Talking about sex, sexual activity, and sexual acts with a child that is outside the scope of developmentally appropriate discussions of sex and sexuality.

- $\quad$ Spurning the child (belittling, denigrating, ridiculing, humiliating in public).

- Terrorizing the child (e.g., placing in unpredictable or chaotic circumstances, placing the child in dangerous situations, etc.). maltreatment involves a non-physical, repeated pattern of caregiver behavior that is likely to be interpreted by the child that they are disliked, unwanted, unloved or rejected by the caregiver and which undermines the child's development, wellbeing and socialization. If severe enough, a single incident by a caregiver could be considered emotionally abusive if deemed emotionally harmful or potentially harmful for a child.

Used interchangeably with psychological neglect, emotional neglect involves caregivers repeated acts of omission and which place their child at risk of emotional harm; including a caregiver's repeated failure to notice, attend to, or respond appropriately to a child or adolescent's feelings.

Refers to a caregiver or parent's inability, refusal, or failure to provide their child with the resources needed for healthy physical development, as well as the level of monitoring and supervision needed to keep the child physically safe from harm or potential harm that is within the control of the caregiver.

Refers to any child or adolescent's exposure to, witnessing or awareness of any incident of violent or threatening behavior between adults who are or have been intimate partners.
- Isolating the child (e.g., confining the child within a room, structure or environment for a non-medically necessary reason; or restricting social interaction within the community, etc).

- Exploiting or corrupting the child's behavior and development (e.g., modeling, permitting or encouraging antisocial behavior, purposefully restricting the child's cognitive development)

- Denying affection when warranted for the child or requested by the child.

- Demonstrating coldness or little-to-no warmth toward the child.

- $\quad$ Ignoring or refusal to engage with the child when demonstrating certain emotions (e.g., anger, sadness, excitement, etc.).

- $\quad$ Providing no praise when warranted

Failure or inability to provide:

- Adequate food for the child's growth and development.

- Clothing adequate for the weather.

- Necessary medical or dental care for the child's development and continued well-being.

- Adequate shelter for the child.

Failure or inability to prevent one's child from witnessing or having an awareness of:

- $\quad$ Physical violence (e.g., slapping, kicking, punching, beating, etc.) between adult caregivers.

- Emotional abuse (e.g., belittling, degradation, humiliation, etc.) between adult caregivers.

- Consensual and/or non-consensual sexual behavior (touching, petting, viewing of pornographic material, intercourse, rape, etc.), between adult caregivers.

- $\quad$ Financial control or abuse of the other caregiver/parent for purposes of socially controlling or harming (e.g., precluding one parent/caregiver from having access to household finances, spending uncharacteristically large sums of money to punish the other parent/caregiver; etc.).

Adapted from: National Institute for Health and Care Excellence (7). 
and adolescents. Second, we discuss how the strict adherence to the principles of family-based treatment (FBT) for EDs has the potential to interfere with a practitioner's ability to readily recognize and respond to any historical or ongoing child maltreatment exposure. We follow this discussion by providing evidence-informed strategies for practitioners to safely recognize and respond to suspected or disclosed child maltreatment when implementing FBT with children, adolescents, and their families in practice.

High rates of a history of child maltreatment have been found among adults with all ED diagnoses, including anorexia nervosa restricting and binge-purge subtypes.(8-10). Most studies focus on female adult samples. In addition, studies vary in their approach to measuring child maltreatment (11). Recent reviews and metaanalyses (8-11) indicate that the prevalence of any form of child maltreatment ranges from 21 to $66 \%$, though much of the literature has focused on physical, sexual, and emotional abuse $(8-11)$. To our knowledge, there is no published study detailing the prevalence of children's exposure to IPV among youth or adults diagnosed with EDs. However, a review of studies based on adult retrospective self-reports indicates that conservatively, at least $10-20 \%$ of youth are exposed to IPV annually; high rates of this exposure have been replicated in a national sample of US youth (12-15). Lastly, it is important for practitioners to be aware that different forms of child maltreatment tend to co-occur (16, 17) and exposure to more than one form of child maltreatment is strongly associated with disordered eating behavior in adults (8) and adolescents (18).

Evidence suggests that the inability to express emotion in healthy and adaptive ways may be the mechanism linking child maltreatment exposure and the development of an ED. Caregivers who maltreat their children show less positive emotion (i.e., joy and warmth), more negative emotion (e.g., anger and sadness), and have less favorable perceptions of emotional expression than their non-maltreating peers. Each of these factors is associated with emotion processing challenges in their offspring, as well as the onset, severity, and duration of child mental health problems and successful intervention (19). Children who experience inconsistent, harsh, dismissive, or overinvolved caregiver responses to their emotions have been shown to demonstrate deficits in emotion processing, including recognizing, understanding (e.g., labeling), and expressing emotion. More specifically, when these caregiver responses occur, the emotional experience of the child is ignored, minimized, or incongruent with their expectation. If this emotional incongruence happens frequently or repeatedly, this can contribute to the internalization of negative beliefs toward emotional expression. Such internalizations may alter the child's cognitive processing of emotion information and lead to the use of maladaptive strategies (e.g., emotional suppression) (20-22) to process emotion, as well as the subsequent development of behavioral and psychological symptoms (e.g., purging, restriction, binge eating, excessive exercise, etc.), to manage their emotion states (23-26). Though this explanatory framework is a promising line of research, additional longitudinal studies capable of disentangling the influence of maltreatment exposure on maladaptive emotion processing and ED development, persistence and intervention are needed.

\section{RECOGNIZING CHILD MALTREATMENT WITHIN THE THERAPEUTIC STANCE OF FBT}

A recent qualitative meta-synthesis highlighted that healthcare and social service providers experience challenges related to recognizing and responding to child maltreatment in their practice (27). Emerging work suggests that this is also the case among ED specialists (28). There are several potential implications of this practice challenge. First, FBT continues to be the first-line intervention for youth diagnosed with anorexia nervosa and bulimia nervosa; $(29,30)$ additional evaluations about the tenability of the intervention for treating binge ED, as well as other-specified feeding and EDs are being explored (3133). As a behaviorally-based intervention, FBT involves several key processes and principles that could complicate practitioners' ability to effectively and efficiently recognize and respond to child maltreatment. These include a non-determinant view of the illness, a non-authoritarian therapeutic stance, empowerment of caregivers to facilitate the recovery process, as well as an initial prioritization on nourishment and symptom interruption (3436). In the context of FBT, an unequivocal belief that caregivers are a positive resource to their child's recovery has the potential to negate the identification of adverse caregiver behavior in the context of a child's physical and psychological vulnerability, as well as magnify the impacts of any ongoing child maltreatment (28). Second, a non-determinant view of the illness may implicitly suggest to practitioners that attending to the relational patterns in the family system is secondary to the emphasis on symptom interruption. However, it is important to note that chronic, cumulative exposure to child maltreatment may lead to enduring vulnerability to ED sequelae. In particular, exposure to child maltreatment has been implicated in suboptimal functioning of the system responsible for neuroendocrine stress regulation-the hypothalamic-pituitaryadrenal (HPA) axis. Emerging evidence indicates that altered HPA-axis functioning has the potential to mediate the onset, severity, and persistence of mental health symptoms, $(37,38)$ including ED pathology (39-42). In addition, recent studies suggest the possibility of protracted psychiatric vulnerability via changes to the HPA-axis among individuals with an ED and a child maltreatment history given the effects of ED symptomology (e.g., starvation, binge-purge cycles) on the neuroendocrine response system $(43,44)$. Thus, recognizing and halting any ongoing child maltreatment exposure is critical to short and long-term recovery from an ED.

Safe recognition and response to child maltreatment refers to the practitioner's use of assessment and therapeutic strategies that limit the possibility of additional harm related to child maltreatment exposure. There are two key considerations relevant to the safe recognition of child maltreatment: (a) 
engaging in an ongoing assessment of child maltreatment risk factors; and (b) being attuned to the interactions between a child and their caregiver. The literature cites several common sources of risk for child maltreatment, which can be understood within an adapted version of Bronfenbrenner's $(45,46)$ ecological model of human health and development. Framed within this model, child maltreatment exposure can be considered a consequence of multiple risk factors at the individual, family, community, and societal-level and which interact to create the conditions in which child maltreatment has a stronger likelihood of occurring $(45,47,48)$. An overview of the risk factors associated with child maltreatment exposure are provided in Figure 1. Briefly, the experience of multiple and chronic stressors within and outside the family system is associated with child maltreatment exposure. For example, stress related to caregiver unemployment may be compounded by a child or caregiver's mental health challenges, which can place caregivers at greater risk of maltreating their children. Changes in family demographics (e.g., pregnancy, martial separation, etc.), as well as chronic family conflict (e.g., custody disputes, disparate caregiving practices, etc.), are contexts in which children are at greater risk of being maltreated. In addition, tolerance for discrimination on the basis of gender, racial, or ethnic identity within one's community, as well as societal social and cultural norms that condone the use of violence can all contribute to the risk of child maltreatment (47-52).

Importantly, all forms of child maltreatment can lack overt indicators of their occurrence. In addition, children and youth with and without maltreatment exposure and who are presenting for ED intervention can exhibit similar emotional and behavioral symptoms. For example, the "alerting features" for child maltreatment listed in the National Institute for Health and Care Excellence (NICE) Guidelines (7) (pg. 9) overlap with the symptoms associated with ED psychopathology (e.g., significant changes in mood, etc.). For these reasons, initial and ongoing assessment of the relational patterns within the family and based on information from multiple family members is crucial for safe and efficient recognition and response. This approach is consistent with those detailed in the FBT manuals, which indicate that a comprehensive assessment that consists of an interview with the child, the caregiver(s), a medical evaluation and the administration of standardized questionnaires is critical. The assessment should include a review of the child's ED symptoms and their onset, family dynamics, as well as the impacts of the illness on the youth's short and long-term goals for academics, peer, and family relationships $(34,36)$.

The FBT manual suggests that practitioners should meet with caregivers separately from the youth. In addition, some time spent with each caregiver alone is important for ensuring that any inquiry related to child maltreatment-and in particular, exposure to IPV - is done safely. The two most common forms of IPV are situational couple violence and intimate terrorism; the former is rooted in couple conflict that escalates to violence and the latter refers to an interactional pattern whereby one partner explicitly attempts to exert general, long-term control, over the other partner; this is known as coercive control (53). In the context of intimate terrorism, coercive control tends to encompass three key characteristics: (a) the use of coercion via demand or threat; (b) the abuser's ability and willingness to follow through on threats; and (c) the surveillance of a victim's activity with the intention to make good on the threats (54). In the context of an FBT assessment, initial interviews with caregivers could raise issues of conflict related to disparate caregiving practices, financial challenges, disagreements about their child's diagnosis, as well as the perceived need for intervention, and other familyrelated challenges, including violence. Given this information, as well as the possibility that violence could intensify in the context of psychosocial stress related to their child's serious illness, $(55,56)$ it is critical that each caregiver be provided an opportunity to meet with the FBT therapist independently from their partner. In doing

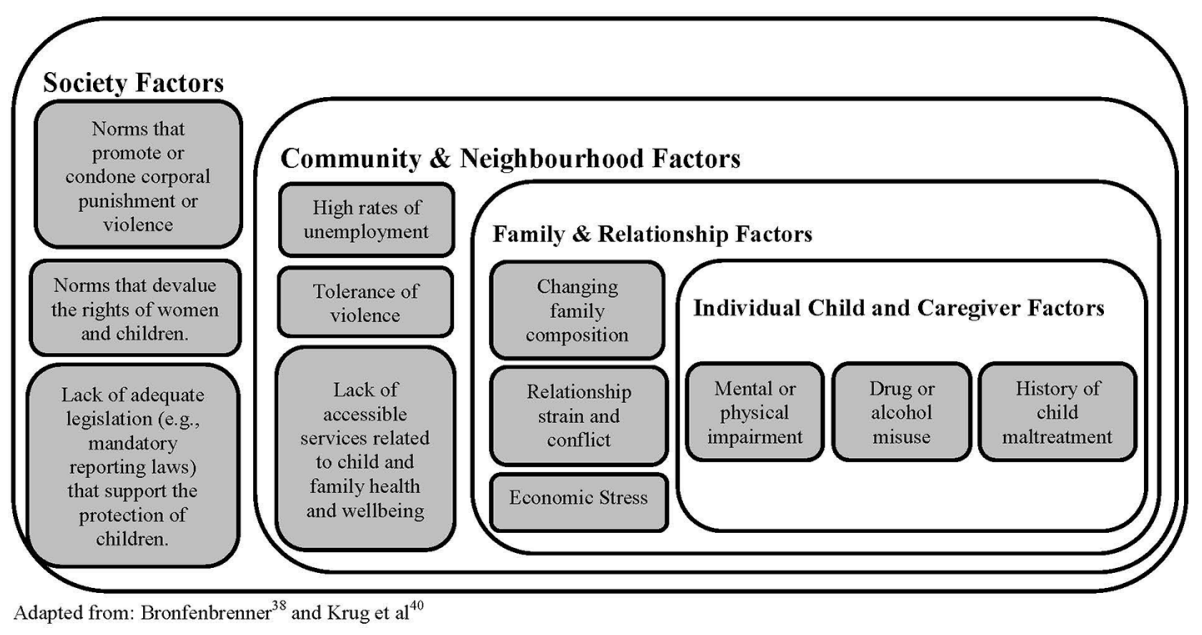

FIGURE 1 | Adapted Ecological Model for Child Maltreatment-Risk Factors. 
so, FBT practitioners can prioritize the safety of any caregiver who is currently experiencing IPV, as well as safely inquire about child exposure to the IPV, and gain a clearer understanding of the dynamics of the caregiver-dyad, which is critical to the FBT process.

\section{Principles for Safely Recognizing Child Maltreatment in FBT}

The principles for safely recognizing child maltreatment in the context of delivering FBT align with the general principles for providing trauma-informed care (TIC). TIC refers to mental health care that is strengths-based and which explicitly seeks to minimize the possibility of iatrogenic effects related to the therapeutic process $(57,58)$. TIC recognizes that exposure to trauma, including child maltreatment, is widespread in the population and that trauma is a strong antecedent of mental health challenges. From a practice perspective, TIC involves the key elements of: (a) ensuring patient collaboration and autonomy; and (b) a commitment to inquiring about and responding to experiences of trauma sensitively and in a way that prioritizes the patient's physical and emotional safety (58). The last decade has seen significant advocacy and discussion related to TIC and though there remains little empirical evidence related to how best to provide TIC in mental health settings, (59) many of its principles parallel recommendations for good clinical practice. Aligning with the key elements of TIC, there are three key principles for safely recognizing child maltreatment in the context of delivering FBT. First, universal screening for child maltreatment is not recommended at any point during FBT. There is no evidence that universal screening for child maltreatment leads to reduced harm, reduced exposure, or optimal outcomes among those who have experienced child maltreatment (60-63). Second, an explicit discussion about the limits of confidentiality with each family member is needed. During the initial assessment, the family should be advised about the limits of confidentiality, jointly. An additional review about the limits of confidentiality should be completed with each family member who participates in an individual interview as part of the assessment process; special attention should be paid to ensuring that youth understand the concept of safety and the limits of confidentiality when issues of safety arise. Third, practitioners should implement a phased inquiry approach. Specifically, practitioner questions about potential child maltreatment exposure should begin with questions focused on the presenting concern (i.e., disordered eating and the onset of symptoms) and then proceed to ask broader questions about well-being and safety. For example, after taking a history of ED symptoms and behaviors, the practitioner might ask: "how does everyone get along at meal times," and then "what about outside of meal times?" These questions might be followed by, "what happens when someone gets upset or angry," and then, "what's the worst thing that has happened?" If the practitioner is considering physical abuse and notices an overt sign for inquiry (e.g., large bruise on a child's leg), in the individual interview with the child, they may say something like, "I see that you have a bruise on your leg. Tell me about that, how did it happen?"
There is no evidence to support routine screening for child maltreatment-in other words, asking everyone a standardized set of questions about child maltreatment exposure, irrespective of presenting signs and symptoms is not supported by evidence. A phased inquiry is the safest and most robust approach for recognizing child maltreatment when signs and symptoms suggest possible exposure.

\section{Opportunities for Ongoing, Phased Inquiry During FBT}

Processes embedded within the delivery of FBT provide additional opportunities for safe, ongoing, inquiry into historical, or ongoing maltreatment. These processes include the discussion of the caregiver dyad's efforts to support their child to interrupt ED symptoms, as well as sibling(s') efforts to support the patient. Practitioners can continue to monitor family dynamics with input from multiple family members. In addition, as detailed in the FBT manuals, each session begins with the practitioner weighing the youth, which is a process that is about $10 \mathrm{~min}$ in duration and completed separately from the caregivers and siblings $(34,36)$. During this time, practitioners can check in with the youth individually. In line with FBT, practitioners can initiate the inquiry by asking youth, during their weigh-in, about how meals and snacks have been going since the last session, as well as asking about any instances of ED behavior (e.g., restriction, exercise, binging, purging, etc.),. This can be followed with open-ended questions that elicit the youth's recall of their caregiver's reactions and interactions with the adolescent (e.g., after you came back from exercising, what happened)? that relate to ED symptomology and the FBT model more generally. Potential "signals" for phased inquiry include the sustainment or worsening of ED or comorbid mental health symptoms, misalignment in reports of progress (or lack thereof) between caregivers, youth and/or their siblings, as well as sudden worsening of the youth's or caregiver's mood, willingness to engage in treatment, as well as their interactions with each other.

\section{RESPONDING WHEN THERE IS A SUSPICION OR DISCLOSURE OF CHILD MALTREATMENT IN THE CONTEXT OF FBT}

Fears of being reported to child protection authorities, as well as the potential outcome of a report, can influence a family's ongoing attendance at sessions. It can also influence the information that youth and caregivers share with their practitioners (64). Importantly, in jurisdictions with mandatory reporting, a suspicion of maltreatment meets the threshold for a report to child protection authorities (although the definition of maltreatment can vary) $(65,66)$. For this reason, the reporting of suspicions and disclosures of child maltreatment constitute a principal (and challenging) component of the response process. 
The NICE guidelines offer important information regarding the distinction between "considering" and "suspecting" child maltreatment (7). To "consider" child maltreatment means that "child maltreatment is one possible explanation" (among others) for the sign or symptom (7). To "suspect" child maltreatment means that the practitioner has a serious level of concern about the possibility of child maltreatment exposure (7). It is not the responsibility of FBT practitioners to obtain proof of child maltreatment exposure and it is important that practitioner's inquiry about signs and symptoms, as well as their responses, do not interfere with the role of child protection professionals. A practitioner's suspicion of maltreatment is justified when the explanation for a sign or symptom is unreasonable or unsuitable. This would mean that the explanation is implausible, inconsistent, or insufficient relative to the child's typical activities, presentation, medical condition, or their developmental trajectory; in these instances, the explanation for the sign or symptom may differ between caregivers, between accounts over time, and/or differs between a child and their caregiver. Importantly, under no circumstances should caregiver preferences for culturally-based practices, rituals or behavior justify emotional or physical harm toward a child. To this end, it is essential for practitioners to be familiar with the legislative requirements concerning the threshold of suspicion and the protection of youth. In addition, it is helpful for practitioners to be aware of, and utilize strategies that can be facilitative of more positive response and reporting experiences. These include empathic responding, appropriate documentation procedures, and ensuring the provision of ongoing support.

\section{Empathic Responding and Mandatory Reporting in FBT}

When child maltreatment is suspected or disclosed, it is important to respond to the information that has been shared in a respectful and compassionate manner. Acknowledging that it can be difficult to talk about these experiences and thanking clients for sharing the information with you is important for respecting the vulnerability of their position and the trust they have placed in you as their practitioner. When a suspicion of child maltreatment has arisen or a disclosure of child maltreatment has been made, it is important to directly communicate your professional concern about what has been shared. Second, the youth and caregiver should be reminded about the limits of confidentiality. Upon doing so, the practitioner can then share that their professional concern warrants a report to the child protection authorities, whose role is to support families. Only in instances where the practitioner is concerned that the caregiver may flee with the youth or when there is an imminent safety risk, should the practitioner withhold their plan to report to child protection professionals from the caregiver or the child. As much as possible and where safe to do so, the non-offending caregiver's participation in the practitioner's report to child protection services (CPS) should be considered and implemented. The youth and their caregiver should be informed about the CPS' potential responses to the report; the practitioner should refrain from making any definitive statements about what will occur. Letting the youth or caregiver know that CPS responses are family-specific, is important. The youth and caregiver can be advised that the practitioner will ask CPS about what they plan to do and that this will be shared where possible with the family. Practitioner transparency about the process, when appropriate and safe to do so, can demonstrate the practitioner's ongoing commitment to supporting the youth and caregiver in the process.

When making the report to CPS, the practitioner should communicate to CPS any and all information that is relevant to their concern about suspected or disclosed child maltreatment; details that are not relevant should not be shared. It is important that an interpretation of what has reportedly occurred not be offered, unless it is within the practitioner's scope of practice (e.g., the individual is an expert in child maltreatment impact). In addition, it is important for the practitioner to clarify with CPS directly what they anticipate for their ongoing role. For example, the practitioner should communicate whether the family will continue to be seen for ED treatment or whether further sessions will be put on hold until after CPS has completed an assessment. In addition, it is possible that a report to CPS will result in the family's termination of the relationship with the FBT practitioner. If a family indicates that they will not return for FBT, as much as possible, providers should offer to connect the youth and caregiver to a new provider whose scope of practice includes ED intervention. The plan should be communicated to the youth and caregiver and the CPS professional. Any concerns that the practitioner has about the delay in treatment for the ED can be made explicit to CPS. It is important for the practitioner to carefully document interactions with the youth, caregiver, and CPS professionals throughout the process. Good documentation practices include: (a) recording verbatim statements by the youth or caregiver; (b) noting discrepancies in the youth's or caregiver's account, if any, and without interpretation; (c) recording a detailed description of the youth's emotional state, behavior, symptoms, or injuries; (d) a note that the call to CPS was made; (e) a note as to whether or not a conversation with the caregiver and/or child about contacting CPS occurred before and/or after the call (if appropriate); and (f) a note about what CPS communicated as potential next steps. Additional guidance for making a report to CPS is available elsewhere $(27,64,67)$.

\section{Providing Support Alongside CPS}

It is important for ED specialists to have familiarity with their local CPS. To date, there are no guidelines as to whether or not FBT should continue when child maltreatment is suspected or disclosed. Plans for ongoing FBT that involves an offending or non-offending caregiver should be informed through collaboration with CPS. If working with a caregiver raises safety concerns or if the CPS professional indicates that caregiver involvement is not possible, there are options that can be discussed with CPS. These include reconstituting the family for the purposes of FBT (e.g., having an aunt/uncle participate in the therapy) or implementing an individual-based psychotherapeutic approach with the youth. For 
example, Adolescent Focused Psychotherapy for Anorexia Nervosa (AFT-AN) (68) is a developmentally-oriented, individual-based model of psychotherapy that focuses on supporting the youth to address negative affective states that are assumed to be driving ED behavior. Compared to FBT, AFT-AN has been shown to be similarly effective in producing full-remission of ED symptoms among youth with anorexia at end-of-treatment (69). Similarly, Cognitive Behavioral Therapy for Eating Disorders (CBT-ED) (70) or CBT Enhanced (CBT-E) (71-74) may be appropriate for youth with anorexia, bulimia, or other-specified food and EDs where caregiver involvement is not appropriate or possible. Importantly, AFT-AN, CBT-ED, and CBT-E have not been evaluated among samples of youth with identified maltreatment exposure, but are listed in guidelines, systematic reviews and meta-analyses as possible interventions for the treatment of youth EDs when FBT is not available, appropriate, or when FBT is contraindicated $(29,30,75,76)$.

In cases where a youth has disclosed exposure to child maltreatment or when exposure has been confirmed by CPS professionals, it is recommended that the FBT practitioner seek consultation with a trauma or child maltreatment expert. A child maltreatment impact assessment may determine that FBT should cease or that adjunctive intervention for trauma-related symptoms is needed. For example, for youth who are exhibiting posttraumatic stress disorder symptoms, a referral to services offering cognitive behavioral therapy (CBT) with a trauma focus (TF-CBT) is appropriate; $(77,78)$ in particular, the TF-CBT model detailed by Cohen, Mannarino, and Deblinger (79-81). Similarly, for youth up to the age of 12 who have been exposed to physical abuse or neglect and are exhibiting externalizing symptoms, the family can be referred to parent-child interaction therapy (PCIT) $(77,82)$. The literature also indicates that in the absence of an available intervention, the provision of psychoeducation about trauma and its associated responses can be an important initial step in addressing trauma-related symptoms (83). Importantly, there is no evidence to support universal screening for exposure to adverse childhood experiences (ACES) - which includes exposure to child maltreatment (84-86). Recent papers report insufficient evidence that ACES screening yields any health benefits for individuals with a history of exposure to child maltreatment (84). In addition, the World Health Organization (87), recommends against universal screening for child maltreatment in the context of mental health and developmental assessments for children and youth. As with the continuation of FBT, any screening, ongoing care or referrals provided to the youth or caregiver for trauma-related symptoms should be clearly documented and made in collaboration with a trauma expert and CPS professionals.

\section{REFERENCES}

1. Oshri A, Rogosch FA, Cicchetti D. Child maltreatment and mediating influences of childhood personality types on the development of adolescent psychopathology. J Clin Child Adolesc Psychol (2013) 42(3):287-301. doi: 10.1080/15374416.2012.715366

2. Norman RE, Byambaa M, De R, Butchart A, Scott J, Vos T. The long-term health consequences of child physical abuse, emotional abuse, and neglect: a

\section{CONCLUSIONS}

There is very little information on how exposure to various types of child maltreatment influences the provision of mental health interventions, including FBT for EDs. ED practitioners need to consider child maltreatment exposure in the assessment of youth; safe inquires and responses build upon the principles of TIC, as well as the communication and psychotherapeutic skills that are already central to their practice. Recognition and response to suspected child maltreatment within the context of FBT involves a clear, developmentally appropriate discussion about the limits of confidentiality at the outset of the therapeutic process. This is followed by a phased inquiry that starts with the presenting concern and which elicits reasonable explanations for signs and symptoms. General questions about interpersonal relationships should be included in the assessment. In those regions where mandatory reporting laws are in place, when practitioners suspect child maltreatment, a report to CPS should be made. Safe responses to suspected maltreatment begin with listening and conveying an emphasis on keeping the child safe. This should be followed by the report to CPS (where required) and the development of a plan for ongoing care related to the youth's mental health, which may or may not include FBT. Critically, FBT practitioners are not required to be experts in the recognition and response to child maltreatment; they are also not required to be experts in the assessment of trauma symptoms or the delivery of trauma-focused care. However, they do have a professional and ethical responsibility to do what they can to ensure the safety and well-being of the children and adolescents for whom they are providing FBT.

\section{AUTHOR CONTRIBUTIONS}

MK wrote the first draft of the manuscript. AG and HM contributed to the conception, editing, and research for the manuscript. All authors contributed to the article and approved the submitted version.

\section{FUNDING}

AG is supported by a Canadian Institutes of Health Research Tier 2 Canada Research Chair and an Ontario Ministry of Research, Innovation and Science Early Researcher Award. HM is supported by the Chedoke Health Chair in Child Psychiatry at McMaster University. systematic review and meta-analysis. PloS Med (2012) 9(11):e1001349. doi: 10.1371/journal.pmed.1001349

3. Afifi TO, MacMillan HL, Boyle M, Taillieu T, Cheung K, Sareen J. Child abuse and mental disorders in Canada. CMAJ (2014) 186(9):E324-332. doi: 10.1503/cmaj.131792

4. Afifi TO, Sareen J, Fortier J, Taillieu T, Turner S, Cheung K, et al. Child maltreatment and eating disorders among men and women in adulthood: Results from a nationally representative United States sample. Int J Eat Disord (2017) 50(11):1281-96. doi: 10.1002/eat.22783 
5. McTavish JR, MacGregor JC, Wathen CN, MacMillan HL. Children's exposure to intimate partner violence: an overview. Int Rev Psychiatry (2016) 28(5):504-18. doi: 10.1080/09540261.2016.1205001

6. Wathen CN, MacMillan HL. Children's exposure to intimate partner violence: Impacts and interventions. Paediatr Child Health (2013) 18 (8):419-22.

7. National Insitute of Health and Care Excellence. Child Maltreatment: When to Suspect Maltreatment in Under 18s. London, UK: National Institute for Health and Care Excellence. Clinical Guideline (CG) (2017). p. 89.

8. Molendijk ML, Hoek HW, Brewerton TD, Elzinga BM. Childhood maltreatment and eating disorder pathology: a systematic review and doseresponse meta-analysis. Psychol Med (2017) 47 (8):1402-1416. doi: 10.1017/ S0033291716003561

9. Pignatelli AM, Wampers M, Loriedo C, Biondi M, Vanderlinden J. Childhood neglect in eating disorders: A systematic review and meta-analysis. J Trauma Dissociation (2017) 18(1):100-15. doi: 10.1080/15299732.2016.1198951

10. Caslini M, Bartoli F, Crocamo C, Dakanalis A, Clerici M, Carra G. Disentangling the Association Between Child Abuse and Eating Disorders: A Systematic Review and Meta-Analysis. Psychosom Med (2016) 78(1):79-90. doi: 10.1097/PSY.0000000000000233

11. Kimber M, McTavish JR, Couturier J, Boven A, Gill S, Dimitropoulos G, et al. Consequences of child emotional abuse, emotional neglect and exposure to intimate partner violence for eating disorders: a systematic critical review. BMC Psychol (2017) 5(1):33. doi: 10.1186/s40359-017-0202-3

12. Carlson BE. Children exposed to intimate partner violence: Research findings and implications for intervention. Trauma Violence Abuse (2000) 1(4):32142. doi: $10.1177 / 1524838000001004002$

13. Finkelhor D, Turner H, Ormrod R, Hamby SL. Violence, abuse, and crime exposure in a national sample of children and youth. Pediatrics (2009) 124 (5):1411-23. doi: 10.1542/peds.2009-0467

14. Finkelhor D, Turner HA, Shattuck A, Hamby SL. Violence, crime, and abuse exposure in a national sample of children and youth: an update. JAMA Pediatr (2013) 167(7):614-21. doi: 10.1001/jamapediatrics.2013.42

15. Finkelhor D, Turner HA, Shattuck A, Hamby SL. Prevalence of Childhood Exposure to Violence, Crime, and Abuse: Results From the National Survey of Children's Exposure to Violence. JAMA Pediatr (2015) 169(8):746-54. doi: 10.1001/jamapediatrics.2015.0676

16. Kim K, Mennen FE, Trickett PK. Patterns and correlates of co-occurrence among multiple types of child maltreatment. Child Fam Soc Work (2017) 22 (1):492-502. doi: $10.1111 / \mathrm{cfs} .12268$

17. Warmingham JM, Handley ED, Rogosch FA, Manly JT, Cicchetti D. Identifying maltreatment subgroups with patterns of maltreatment subtype and chronicity: A latent class analysis approach. Child Abuse Negl (2019) 87:28-39. doi: 10.1016/j.chiabu.2018.08.013

18. Kimber M, Tanaka M, Gonzalez A, Couturier J, MacMillan HL. The differential and cumulative impacts of five forms of child maltreatment on disordered ating behaviour among a representative sample of Canadian youth [Poster Presentation]. Paper presented at: 25th Annual Eating Disorders Research Society Meeting 2019; Chicago, IL.

19. Beeghly M, Cicchetti D. Child Maltreatment, Attachment, and the Self System - Emergence of an Internal State Lexicon in Toddlers at High Social Risk. Dev Psychopathol (1994) 6(1):5-30. doi: 10.1017/ S095457940000585X

20. Milojevich HM, Haskett ME. Longitudinal associations between physically abusive parents' emotional expressiveness and children's self-regulation. Child Abuse Negl (2018) 77:144-54. doi: 10.1016/j.chiabu.2018.01.011

21. Greenberg L. Emotion and Cognition in Psychotherapy: The Transforming Power of Affect. Can Psychol (2008) 49(1):49-59. doi: 10.1037/07085591.49.1.49

22. Meesters C, Muris P. Perceived parental rearing behaviours and coping in young adolescents. Pers Indiv Differ (2004) 37(3):513-22. doi: 10.1016/ j.paid.2003.09.022

23. Schuetzmann M, Richter-Appelt H, Schulte-Markwort M, Schimmelmann BG. Associations among the perceived parent-child relationship, eating behavior, and body weight in preadolescents: Results from a communitybased sample. J Pediatr Psychol (2008) 33(7):772-82. doi: 10.1093/jpepsy/ jsn002
24. Vandewalle J, Moens E, Braet C. Comprehending emotional eating in obese youngsters: the role of parental rejection and emotion regulation. Int $J$ Obes (Lond) (2014) 38(4):525-30. doi: 10.1038/ijo.2013.233

25. Peris TS, Miklowitz DJ. Parental Expressed Emotion and Youth Psychopathology: New Directions for an Old Construct. Child Psychiatry Hum Dev (2015) 46(6):863-73. doi: 10.1007/s10578-014-0526-7

26. Vandewalle J, Moens E, Bosmans G, Braet C. The effect of parental rejection on the emotional eating behaviour of youngsters: A laboratory-based study. Appetite (2017) 108:219-25. doi: 10.1016/j.appet.2016.10.007

27. McTavish JR, Kimber M, Devries K, Colombini M, MacGregor JCD, Wathen $\mathrm{CN}$, et al. Mandated reporters' experiences with reporting child maltreatment: a meta-synthesis of qualitative studies. BMJ Open (2017) 7(10):e013942. doi: 10.1136/bmjopen-2016-013942

28. Kimber M, McTavish JR, Couturier J, Le Grange D, Lock J, MacMillan HL. Identifying and responding to child maltreatment when delivering familybased treatment-A qualitative study. Int J Eat Disord (2019) 52(3):292-8. doi: 10.1002/eat.23036

29. Lock J, La Via MC. Issues AAoCaAPCoQ. Practice parameter for the assessment and treatment of children and adolescents with eating disorders. J Am Acad Child Adolesc Psychiatry (2015) 54(5):412-25. doi: 10.1016/ j.jaac.2015.01.018

30. National Institute of Health and Care Excellence. Eating Disorders: Recognition and Treatment. London, UK: National Insitute for Health and Care Excellence. Clinical Guideline (CG) (2017). p. 89.

31. Rienecke RD. Family-based treatment of eating disorders in adolescents: current insights. Adolesc Health Med Ther (2017) 8:69-79. doi: 10.2147/ AHMT.S115775

32. Loeb KL, Le Grange D, Lock J. Family therapy for adolescent eating disorders: New applications. New York, NY: Routledge (2015).

33. Murray SB, Karwoski-Anderson L, Cohn L. Innovations in family therapy for eating disorders: Novel treatment developments, patient insights, and the role of carers. New York, NY: Routledge (2016).

34. le Grange D, Lock J. Treating bulimia in adolescents: A family-based approach. New York, NY: The Guilford Press (2007).

35. Lock J, le Grange D. Family-based treatment of eating disorders. Int J Eat Disord (2005) 37 Suppl:S64-67:S87-69. doi: 10.1002/eat.20122

36. Lock J, le Grange D. Treatment manual for anorexia nervosa: A family-based approach. 2nd Edition. New York, NY: The Guilford Press (2013).

37. Purewal Boparai SK, Au V, Koita K, Lee Oh D, Briner S, Burke Harris N, et al. Ameliorating the biological impacts of childhood adversity: A review of intervention programs. Child Abuse Negl (2018) 81:82-105. doi: 10.1016/ j.chiabu.2018.04.014

38. Nelson CA 3rd. Hazards to Early Development: The Biological Embedding of Early Life Adversity. Neuron (2017) 96(2):262-6. doi: 10.1016/ j.neuron.2017.09.027

39. Monteleone AM, Monteleone P, Esposito F, Prinster A, Ruzzi V, Canna A, et al. The effects of childhood maltreatment on brain structure in adults with eating disorders. World J Biol Psychiatry (2019) 20(4):301-9. doi: 10.1080/ 15622975.2017.1395071

40. Monteleone AM, Monteleone P, Serino I, Scognamiglio P, Di Genio M, Maj M. Childhood trauma and cortisol awakening response in symptomatic patients with anorexia nervosa and bulimia nervosa. Int J Eat Disord (2015) 48(6):615-21. doi: 10.1002/eat.22375

41. Monteleone AM, Monteleone P, Volpe U, De Riso F, Fico G, Giugliano R, et al. Impaired cortisol awakening response in eating disorder women with childhood trauma exposure: evidence for a dose-dependent effect of the traumatic load. Psychol Med (2018) 48(6):952-60. doi: 10.1017/ S0033291717002409

42. Monteleone AM, Patriciello G, Ruzzi V, Cimino M, Del Giorno C, Steardo L, et al. Deranged emotional and cortisol responses to a psychosocial stressor in anorexia nervosa women with childhood trauma exposure: Evidence for a "maltreated ecophenotype"? J Psychiatr Res (2018) 104:39-45. doi: 10.1016/ j.jpsychires.2018.06.013

43. Focker M, Stalder T, Kirschbaum C, Albrecht M, Adams F, de Zwaan M, et al. Hair Cortisol Concentrations in Adolescent Girls with Anorexia Nervosa are Lower Compared to Healthy and Psychiatric Controls. Eur Eat Disord Rev (2016) 24(6):531-5. doi: 10.1002/erv.2466 
44. Lelli L, Castellini G, Cassioli E, Monteleone AM, Ricca V. Cortisol levels before and after cognitive behavioural therapy in patients with eating disorders reporting childhood abuse: A follow-up study. Psychiat Res (2019) 275:269-75. doi: 10.1016/j.psychres.2019.03.046

45. Bronfenbrenner U. The Ecology of Human Development: Experiments by Nature and Design. Cambridge, MA: Harvard University Press (1979).

46. Tudge JRH, Mokrova I, Hatfield BE, Karnik RB. Uses and misuses of Bronfenbrenner's Biological Theory of Human Development. J Family Theory Rev (2009) 1(4):198-210. doi: 10.1111/j.1756-2589.2009.00026.x

47. Krug EG, Mercy JA, Dahlberg LL, Zwi AB. The world report on violence and health. Lancet (2002) 360(9339):1083-8. doi: 10.1016/S0140-6736 (02)11133-0

48. Stith SM, Liu T, Davies LC, Boykin EL, Alder MC, Harris JM, et al. Risk factors in child maltreatment: A meta-analytic review of the literature. Aggress Violent Behav (2009) 14(1):13-29. doi: 10.1016/j.avb.2006.03.006

49. Murphy S, McElroy E, Elklit A, Shevlin M, Murphy J, Hyland P, et al. Parental risk factors for childhood maltreatment typologies: A data linkage study. Eur J Trauma Dissociation (2018) 2(4):189-95. doi: 10.1016/j.ejtd.2018.04.001

50. Viola TW, Salum GA, Kluwe-Schiavon B, Sanvicente-Vieira B, Levandowski ML, Grassi-Oliveira R. The influence of geographical and economic factors in estimates of childhood abuse and neglect using the Childhood Trauma Questionnaire: A worldwide meta-regression analysis. Child Abuse Negl (2016) 51:1-11. doi: 10.1016/j.chiabu.2015.11.019

51. Assink M, Spruit A, Schuts M, Lindauer R, van der Put CE, Stams GJM. The intergenerational transmission of child maltreatment: A three-level meta-analysis. Child Abuse Negl (2018) 84:131-45. doi: 10.1016/j.chiabu.2018.07.037

52. Mulder TM, Kuiper KC, van der Put CE, Stams GJM, Assink M. Risk factors for child neglect: A meta-analytic review. Child Abuse Negl (2018) 77:198-210. doi: 10.1016/j.chiabu.2018.01.006

53. Johnson MP. A typology of Domestic Violence: Intimate Terrorism, Violent Resistance, and Situational Couple Violence. Lebanon, NH: Northeastern University Press (2008).

54. Dutton M, Goodman L. Coercion in intimate partner violence: Toward a new conceptualization. Sex Roles (2005) 5:743-56. doi: 10.1007/s11199-005-4196-6

55. Hillege S, Beale B, McMaster R. Impact of eating disorders on family life: individual parents' stories. J Clin Nurs (2006) 15(8):1016-22. doi: 10.1111/ j.1365-2702.2006.01367.x

56. Fox JR, Dean M, Whittlesea A. The Experience of Caring For or Living with an Individual with an Eating Disorder: A Meta-Synthesis of Qualitative Studies. Clin Psychol Psychother (2017) 24(1):103-25. doi: 10.1002/cpp. 1984

57. Sweeney A, Perot C, Callard F, Adenden V, Mantovani N, Goldsmith L. Out of the silence: towards grassroots and trauma-informed support for people who have experienced sexual violence and abuse. Epidemiol Psychiatr Sci (2019) 28 (6):598-602. doi: 10.1017/S2045796019000131

58. Sweeney A, Taggart D. (Mis)understanding trauma-informed approaches in mental health. J Ment Health (2018) 27(5):383-7. doi: 10.1080/ 09638237.2018.1520973

59. Oram S, Boyce N, Howard LM. Mental health and violence: opportunities for change. Lancet Psychiatry (2019) 6(7):558-9. doi: 10.1016/S2215-0366 (19)30186-5

60. World Health Organization. mhGAP Intervention Guide for Mental, Neurological, and Substance Use Disorders in Non-Sepcialized Health Settings. Geneva, Switzerland: World Health Organization (2016).

61. World Health Organization. Health Care for Women Subjected to Intimate Partner Violence or Sexual Violence: A Clinical Handbook. Geneva, Switzerland: World Health Organization (2014).

62. McTavish JR, Gonzalez A, Santesso N, MacGregor JCD, McKee C, MacMillan H. Identifying children exposed to maltreatment: a systematic review update. BMC Pediatr (2018) 20:113. doi: 10.1186/ s12887-020-2015-4

63. Bailhache M, Leroy V, Pillet P, Salmi LR. Is early detection of abused children possible?: a systematic review of the diagnostic accuracy of the identification of abused children. BMC Pediatr (2013) 13:202. doi: 10.1186/1471-2431-13-202
64. McTavish JR, Kimber M, Devries K, Colombini M, MacGregor JCD, Wathen N, et al. Children's and caregivers' perspectives about mandatory reporting of child maltreatment: a meta-synthesis of qualitative studies. BMJ Open (2019) 9(4):e025741. doi: 10.1136/bmjopen-2018-025741

65. Mathews B, Kenny MC. Mandatory reporting legislation in the United States, Canada, and Australia: a cross-jurisdictional review of key features, differences, and issues. Child Maltreat (2008) 13(1):50-63. doi: 10.1177/ 1077559507310613

66. Dubowitz H. World Perspectives on Child Abuse. 11th Edition. Aurora, CO: International Society for the Prevention of Child Abuse and Neglect (ISPCAN) (2014).

67. McTavish JR, MacMillan HL. Briefing Note: Mandatory Reporting of Child Maltreatment. Hamilton Ontario: McMaster University (2019).

68. Fitzpatrick KK, Moye A, Hoste R, Lock J, Le Grange D. Adolescent focused psychotherapy for adolescents with anorexia nervosa. J Contemp Psychother (2010) 40(1):31-9. doi: 10.1007/s10879-009-9123-7

69. Lock J, Le Grange D, Agras WS, Moye A, Bryson SW, Jo B. Randomized clinical trial comparing family-based treatment with adolescent-focused individual therapy for adolescents with anorexia nervosa. Arch Gen Psychiatry (2010) 67(10):1025-32. doi: 10.1001/archgenpsychiatry. 2010.128

70. Waller G, Cordery H, Corstorphine E, Hinrichsen H, Lawson R, Mountford V, et al. Cognitive Behavioral Therapy for Eating Disorders: A comprehensive treatment guide. London, UK: Cambridge University Press (2007).

71. Fairburn CG. Cognitive Behavior Therapy and Eating Disorders. New York, NY: Guilford Press (2008).

72. Dalle Grave R, Calugi S, Doll HA, Fairburn CG. Enhanced cognitive behaviour therapy for adolescents with anorexia nervosa: an alternative to family therapy? Behav Res Ther (2013) 51(1):R9-R12. doi: 10.1016/ j.brat.2012.09.008

73. Dalle Grave R, Calugi S, El Ghoch M, Conti M, Fairburn CG. Inpatient cognitive behavior therapy for adolescents with anorexia nervosa: immediate and longer-term effects. Front Psychiatry (2014) 5:14. doi: 10.3389/ fpsyt.2014.00014

74. Dalle Grave R, Calugi S, Sartirana M, Fairburn CG. Transdiagnostic cognitive behaviour therapy for adolescents with an eating disorder who are not underweight. Behav Res Ther (2015) 73:79-82. doi: 10.1016/ j.brat.2015.07.014

75. de Jong M, Schoorl M, Hoek HW. Enhanced cognitive behavioural therapy for patients with eating disorders: a systematic review. Curr Opin Psychiatry (2018) 31(6):436-44. doi: 10.1097/YCO.0000000000000452

76. Couturier J, Isserlin L, Norris M, Spettigue W, Brouwers M, Kimber M, et al. Canadian practice guidelines for the treatment of children and adolescents with eating disorders. J Eat Disord (2020) 8:4. doi: 10.1186/ s40337-020-00307-2

77. McMaster University. VEGA Project Family Violence Education Resources. (2019). [cited 2020 June 8]. Available from: https://vegaproject.mcmaster.ca/.

78. World Health Organization. Responding to children and adolescents who have been sexually abused: WHO Clinical Guidelines. Geneva, Switzerland: World Health Organization (2017).

79. Deblinger E, Mannarino AP, Cohen JA, Runyon MK, Steer RA. Traumafocused cognitive behavioral therapy for children: impact of the trauma narrative and treatment length. Depress Anxiety (2011) 28(1):67-75. doi: 10.1002/da.20744

80. Cohen JA, Mannarino AP, Deblinger E. Treating Trauma and Traumatic Grief in Children and Adolescents. New York, NY: Guilford Press (2006).

81. VEGA Project. Child Maltreatment Systematic Review Summary. Hamilton, ON: McMaster University (2016).

82. National Institute of Health and Care Excellence. Child abuse and neglect. London, UK: National Institute for Health and Care Excellence. Clinical Guideline (CG) (2017). p. 76.

83. Karatzias T, Ferguson S, Chouliara Z, Gullone A, Cosgrove K, Douglas A. Effectiveness and acceptability of group psychoeducation for the management of mental health problems in survivors of child sexual abuse (CSA). Int J Group Psychother (2014) 64(4):492-514. doi: 10.1521/ ijgp.2014.64.4.492 
84. Campbell TL. Screening for adverse childhood experiences (ACEs) in primary care: A cautionary note. JAMA (2020) 323(23):E1-2. doi: 10.1001/ jama.2020.4365

85. McLennan JD, MacMillan HL, Afifi TO, McTavish J, Gonzalez A, Waddell C. Routine ACEs screening is NOT recommended. Paediatr Child Health (2019) 24(4):272-3. doi: 10.1093/pch/pxz042

86. Anda RF, Porter LE, Brown DW. Inside the Adverse Childhood Experience Score: Strengths, limitations, and misapplications. Am J Pev Med (2020), S0749-3797(20)30058-1. doi: 10.1016/j.amepre.2020. 01.009

87. World Health Organization. WHO mhGAP Guideline Update: Update of the Mental Health Gap Action Programme (mhGAP) Guideline for Mental, Neurological and Substance Use Disorders. Geneva, Switzerland: World Health Organization (2015).
Conflict of Interest: MK and HM report that they have received funds from the Public Health Agency of Canada to develop, disseminate, and evaluate educational resources on family violence, including child maltreatment.

The remaining authors declare that the research was conducted in the absence of any commercial or financial relationships that could be construed as a potential conflict of interest.

Copyright (c) 2020 Kimber, Gonzalez and MacMillan. This is an open-access article distributed under the terms of the Creative Commons Attribution License (CC BY). The use, distribution or reproduction in other forums is permitted, provided the original author(s) and the copyright owner(s) are credited and that the original publication in this journal is cited, in accordance with accepted academic practice. No use, distribution or reproduction is permitted which does not comply with these terms. 